\title{
1. Introduction: Legal theory as media theory
}

\section{THE DEPENDENCE OF (MEDIA) THEORY ON MEDIA}

It may be the case that no medium can ever be defined except in contrast to another medium. Certainly, this is true of the relationship between speech and writing: it is the written word that is first able to comprehend speech. Jacques Derrida articulated something like this in his book Of Grammatology (1967), ${ }^{1}$ and this dependency of spoken language on writing is rooted not least in the fact that the spoken word is fleeting, and that everything which can be said immediately disappears again in the wake of its articulation. Thus we are first able to recognize an object of language distinct from speaking (from linguistic usage, from verbal communication, from the act of speech) only when the fluctuance of spoken language is arrested and fixed in the medium of the written word. In other words, "the continuous disappearance of the word in the flow of communication must be stopped, and this inevitably brings writing into play."2 Reflecting on the nature of language therefore becomes possible only after a practice of writing has been established which suspends the ephemerality of the word in the rigidity of script, allowing language to be understood as a seemingly stable "object" of philosophical, theoretical, and scientific thought; historically, this first occurred during the time of Plato. ${ }^{3}$ Only once writing exists can language become subject to linguistic study and its grammar visualized. ${ }^{4}$ Indeed, a strong case can even be made that the linguistic-semiologic understanding of language as a "system of signs" 5 first becomes possible with the development of printing, as it is precisely the culture and epistemology of the printing press which suggests that language may be clearly visualized and explained as a "system."

Just as the evolution of certain concepts in philosophy, linguistics, and semiology is contingent on media such as the written word and the printing press, so too is the emergence of media theory related to the rise of electronic media. Growing intellectual

J. Derrida, Of Grammatology (1976) $6 \mathrm{f}$.

C. Stetter, Schrift und Sprache (1997) 129, 126 (quotation).

3 C. Stetter, System und Performanz (2005) 41; id. (fn. 2) 319 ff.; E. A. Havelock, Preface to Plato (1963) 219, 224.

4 S. Krämer, "Mündlichkeit/Schriftlichkeit" (2005) 192, 194 ("Writing makes visible grammatical relationships; it visualizes language as a system of elements assembled according to rules."); E. A. Havelock, The Muse Learns to Write (1986) 112.

5 F. de Saussure, Course in General Linguistics (2011) 15.

6 For the interrelation between system formation and print culture cf. N. Luhmann, Theory of Society I (2012) 176 f., 328 ff.; Stetter (fn. 2) 66 ff.; J. Assmann, Cultural Memory and Early Civilization (2011) 140 f.; W. J. Ong, Ramus [1958] (2004) 316 f.; cf. also the preface by A. Johns, ix. 
interest in the characteristics of orality (speech-song, gesture, dance, rhythm, etc.) during the 1920s, such as one finds in Marcel Jousse's Le Style oral rhythmique et mnémotechnique chez le Verbo-moteurs (1925) or Milman Parry's L'Épithète traditionelle dans Homer (1928), may well have been heavily influenced by the advent of radio and the concomitant possibility of transmitting information to faraway recipients. The classical scholar Eric A. Havelock, who can be considered one of the founding fathers of media theory alongside Marshall McLuhan, Walter J. Ong, and Harold Innis, refers to this experience, so novel for his generation, in The Muse Learns to Write (1986), a late self-reflection on the sum total of his thought. Here Havelock specifically discusses his and his students' peculiar fascination with the public broadcast in Toronto of a radio address by Hitler on the occasion of the German Army's invasion of Poland in 1939: Hitler's strident, vehement, staccato, ejaculatory sentences, whose claims to power were clearly and intelligibly articulated, even if their precise meaning was ultimately incomprehensible to English-speaking listeners. ${ }^{7}$ In the case of media theory, however, the relationship between media is more complicated and reflexive than in the case of writing and printing. While print culture only rarely reflects on its primary medium, that of the printed book, media theory knows that its constitutive context is the emergence of film and radio. At the same time, it also knows that, as theory, it remains reliant on the medium of the book, and that in content it is unable to avoid for example, in depictions of oral cultures - the use of concepts and metaphors whose meanings are woven into the patterns of the conventions and epistemology of literacy. ${ }^{8}$

Further evidence of media theory's double dependence on media - as the subconscious impetus for engaging with questions of media on the one hand, and as the trigger for the simultaneously incipient awareness that theoretical representations of language and orality are reliant upon writing and printing on the other - is easy to find. Havelock himself surmises that emerging interest in media and media theory in widely different theoretical contexts over the course of the 1960s - books and articles like La Pensée Sauvage (Claude Lévi-Strauss, 1962), The Gutenberg Galaxis (Marshall McLuhan, 1963), and The Consequences of Literacy (Jack Goody/Ian Watt, 1963) must more or less be understood in the context of new mass media. ${ }^{9}$ One could point to Karl Bühler's Theory of Language (1934) as evidence of this hypothesis: Bühler already situates the "concrete acoustic phenomenon" of language within a binary system of "sender" and "receiver." 10 With this theoretical construction, and with a terminology in which not only the central concepts of early radio culture, but also terms such as "system," "control," and "signal" play a central role, Bühler anticipates a

7 Havelock (fn. 4) 31, 32 ("The strident, vehement, staccato sentences clanged out and reverberated and chased each other along, series after series, flooding over us, battering us, half drowning us, and yet kept us rooted there listening to a foreign tongue which we somehow could nevertheless imagine that we understood. The oral spell had been transmitted in the twinkling of an eye, across thousands of miles, had been automatically picked up and amplified and poured over us").

8 Cf. Havelock (fn. 4) 65 ("Literate habits and assumptions and language are the warp and woof of modern existence"), and W. J. Ong, The Presence of the Word (1967) 19 ("We are the most abject prisoners of the literate culture in which we have matured").

9 Havelock (fn. 4) $32 \mathrm{f}$.

10 Cf. K. Bühler, Theory of Language [1934] (2011) $34 \mathrm{f}$. 
number of cybernetic and information-theory models that are of great relevance to current debates in media theory. For modern media theory debates have been decisively shaped by computer technology and its accompanying culture and epistemology of networks, ${ }^{11}$ which first took form in the study of cybernetics during the 1930s and 40s (Ian Turing, John von Neumann, Norbert Wiener, the Macy conferences, etc.) and the beginnings of which can be traced back to early mathematical reflections on the predictability, consistency, and (in-)completeness of formal systems since the turn of the twentieth century (Kurt Gödel, David Hilbert, the Vienna Circle, etc.).

\section{THE CULTURE AND EPISTEMOLOGY OF NETWORKS}

\section{Social Epistemology}

In the cybernetic debates of the mid-twentieth century, the experience of information as being processed in symbolic machines and computers led to the insight that knowledge is not the product of the unpresupposing "cognition" of a perceptive subject (a Diogenes in his jar, a Robinson Crusoe, a monadic entity, a Cartesian cogito, a transcendental self, etc.), but rather is generated from knowledge that is already available. The reflexive form of the procedures for acquiring certain knowledge (as opposed to mere opinion) can thus be described - to borrow a term that has long been in common use in the French-language literature - as "epistemology." The choice of this term should from the outset signal a certain distance from the idealist tradition of epistemological theory as well as from certain strains of analytic philosophy in which "knowledge" and "cognition" are, on the one hand, too quickly associated with the powers of (individual) consciousness and, on the other, too far removed from aesthetic perception, in order that the integrity and objectivity of knowledge not be contaminated with aspects of sensuality. By contrast, Steve Fuller's "social epistemology," along with the study of systems theory as developed by Niklas Luhmann, consistently emphasizes that processes of knowledge generation are inextricably embedded in social contexts. ${ }^{12}$ Given that human beings inevitably come to rely on interactions with others, not only in practical behavioral contexts but also in the case of cognitive activities, the essence of such an understanding of "epistemology" can be summed up in Sybille Krämer's assertion that all epistemology turns out to be "social epistemology through and through."13

If one accepts this switch to social epistemology, it then becomes easy to open up legal theory to the current discussions and research of cultural and media theory. On the

11 For the new "logic of networks" cf. A-L. Barabási, Linked (2002); J.-M. Guéhenno, The End of the Nation-State (1995) 33, 56 f., and M. Castells, Communication Power (2009) $19 \mathrm{ff}$.

12 Cf. St. Fuller, Social Epistemology (2002) in particular 175 ff.; N. Luhmann, Die Wissenschaft der Gesellschaft (1990) 122, 597 ff. (on the need for a "structural coupling" of science and society).

13 S. Krämer, Medium, Messenger, Transmission (2015) 162; see also L. Daston/P. Galison, Objectivity (2007) 39 ff., 368; and H.-J. Rheinberger, On Historicizing Epistemology (2010) 79 ff. ; K.-H. Ladeur, Negative Freiheitsrechte und gesellschaftliche Selbstorganisation (2000) $106 \mathrm{ff}$. (from a legal theory perspective). 
one hand, turning away from the (individual) consciousness-oriented epistemological theories of the modern era makes a historical dimension of epistemology possible, so that "historical epistemology" can then be said to include contemplation of the historical conditions "under which, and the means with which, things are made into objects of knowledge. It focuses thus on the process of generating scientific knowledge and the ways in which it is initiated and maintained." 14 To study legal theory as media theory would then necessarily mean both making media themselves the objects of jurisprudential knowledge and, conversely, reconstructing the ruptures and displacements brought about by the rise of new media within the impersonal and anonymous process of cultural evolution with regard to their consequences for the collective ordering of practical knowledge. As demonstrated in the above examples of the discipline's early development (Havelock, Ong, Innis, McLuhan, etc.), media theory places such strong emphasis on cultural and medial conditions of knowledge that one is almost compelled to speak of "cultural" or "medial" rather than "social" epistemology. In place of the supposition that there could exist such a thing as "pure" knowledge wholly independent of a given society's cultural and medial conditions of reproduction, media theory proceeds from the hypothesis that knowledge is always already socially, culturally, and medially embedded, and that perception and society, cognition and culture, knowledge and media are always already entangled. Against the background of this initial hypothesis, this introductory chapter intends to demonstrate that there is an intrinsic connection between the rise of computers and the new culture and epistemology of the network. Since the 1960s, even the most divergent theories of both the human and natural sciences have all reacted - in a more or less reflexive mode - to the increasing use of computers and their increasingly decentralized connection in networks.

\section{Connectivity of Knowledge Fragments}

The new culture of networks introduces the transition to a new post-ontological, post-metaphysical, and post-modern epistemological situation, an epoch "in which reality can no longer be conceived of as a structure solidly tied to a sole foundation." 15 Just as Romanticism, with its penchant for the poetological, stresses the autonomy of aesthetic speech vis-à-vis philosophical reason (for example in Friedrich Schlegel's new mythology, which praises the "primordial chaos of human nature" as symbolized by the "colorful swarm of the old gods"), ${ }^{16}$ the epistemology of the present age substitutes a "connectivity of knowledge fragments" for print culture's older notion of knowledge unified in a subject. The illusion of unmediated access "from a one-point perspective to the one reality," 17 which evades any attempt at a unified, complete, or

14 Rheinberger (fn. 13) 2, 3. emphases in the original); see also id., Iterationen (2005) $101 \mathrm{ff} ., 125$.

15 G. Vattimo, After Christianity (2002) 5; id., Weltverstehen - Weltverändern (2001) 50 ff., 60 ("the world actually and ever more comprehensively dissolved in a play of interpretations").

16 Cf. K.-H. Bohrer, "Vernunft, Zeitlichkeit und Ästhetik" (2009) 509 ff., 512.

17 K.-H. Ladeur, "Soziale Epistemologie der Demokratie" (2009) 143; S. Lavaud-Forest, "Perspectives numériques" (2009) 55 ff. 
conclusive description, is thereby destroyed. Even under these new epistemological conditions, knowledge does not simply disintegrate into pieces that would operate wholly independently of and exhibit no points of contact with each other. The old unity of knowledge has been lost, however, to the extent that knowledge has become more fluid and polycontextual, and now appears as a "unit" only in the form of temporary combinations of knowledge fragments into webs, meshes and other such configurations. Put another way, a vertical (tree-shaped) organization of knowledge that is relatively stable over time and claims to be conclusive and complete has been replaced by a self-referential dynamic of combinatorial knowledge generation, a fluid network of knowledge created out of knowledge. The "stable, tangible data-carriers" of printed books and libraries have been displaced by a script of "electronic impulses," "a fluid system of [the] international self-organization" of data. ${ }^{18}$

In the realm of philosophy of science, this transition to a loose linking of "partial forms" of knowledge that can no longer be concentrated in a central authority may already be found in the work of Michael Polanyi, particularly in his notion of the horizontal organization of knowledge in a "society of explorers," 19 which ushers in a scientific culture marked by "chains of overlapping neighborhoods" 20 and no longer founded on a fixed, homogenous store of universally shared rules, conventions, and values. Cornelius Castoriadis expresses similar ideas and likewise speaks of a "hitherto unsuspected type of stratification" of knowledge "in terms of an organization of layers that in part adhere together, in terms of an endless succession in depth of layers of being that are always organized but never completely." 21 For certain recent movements in theoretical and practical philosophy, the transition to an epistemology of networks corresponds to the collapse of the idea of a hierarchical reason as the central supervisory authority for all knowledge. In the work of Bernhard Waldenfels and others, the hierarchical reason of print culture, which had been based on the model of an individual subject with an autonomous existence outside the relationship and communication networks that necessarily constitute him, is replaced by a notion of "lateral universality" understood as a "constellation with series, chains, networks, that is, with pervasive and articulated relations and open points of access." 22 Wolfgang Welsch, adapting a term from Gilles Deleuze and Félix Guattari's A Thousand Plateaus: Capitalism and Schizophrenia (1980), refers to this new, open, and incomplete rationality as "transversal reason," defined as the rationality of "implicit linkages" and "explicit transitions," as reason that is concerned with "generating transversal complexes" but not "imposing upon [them] any fixed a priori principle." ${ }^{3}$ The cultural

18 A. Assmann, Cultural Memory and Western Civilization (2011) 344; Ladeur (fn. 17) 135 ff., 149 ("logic of streaming"); I. Augsberg, Die Lesbarkeit des Rechts (2009) 132 f.

19 M. Polanyi, The Tacit Dimension (1966) 55 ff.; J. H. Gill, The Tacit Mode (2000) 63, 92.

20 Polanyi (fn. 19) 72 ("chains of overlapping neighborhoods"); from a legal theory perspective: K.-H. Ladeur, Das Umweltrecht der Wissensgesellschaft (1995) 31, 35.

21 C. Castoriadis, Crossroads in the Labyrinth (1984) 172; cf. also Barabási (fn. 11) $201 \mathrm{f}$.

22 B. Waldenfels, Order in the Twilight (1996) 136-7, 18; see also id., Phenomenology of the Alien (2011) 10 f.; from a legal theory perspective: K.-H. Ladeur, Postmoderne Rechtstheorie (1992) 39.

23 W. Welsch, Unsere postmoderne Moderne (1991) 310 f.; id., Vernunft (1996) 761, 763. 
economy of Boris Groys reaches a similar conclusion with respect to cultural and artistic endeavors: cultural knowledge has now become so large, complex, and specialized that it is no longer possible for human consciousness to have mastery over it. Rather, every author becomes caught in a vortex of endlessly re-describing already existing descriptions and traditions, from which there is no escape. "In contemporary civilization, doubtless no discourse can be lordly, sovereign, authoritative, or have the force of law." 24

In the realm of sociology, Niklas Luhmann likewise describes the loss of a single rationality that encompasses the whole world in the language of his theory of social systems. The days when it was possible to deduce social reality from a principle lie behind us. Any and all access to social reality is per se bound to a multitude of communications systems and the knowledge that accompanies them. ${ }^{25}$ Social communications systems, however, necessarily function self-referentially, according to their own respective rationality, and this drift grows stronger the more social systems become aggregated. It is precisely the functional systems of modern society, such as economy, politics, and law, which can thus never attain real reality themselves, but rather can only utilize it as a point of re-entry into the already-operating system. Given this, rationality can now be realized only as "system rationality" and no longer as the absolute rule of reason, precisely because the use of a term like reason remains contingent on an operating user system that is never fully transparent to itself, not even as a "cognitive" system. ${ }^{26}$ As a result, even the form in which theories are constructed has changed. Theory is no longer deduced from a principle (a beginning, an origin, a final ground) as in Hegel's time, but rather is obtained through the combination of a multiplicity of "theoretical bits" and condensed into the most consistent possible web of differences through constant testing, adjustment and rearrangement. Theory is now litigated by a form of "thinking in networks" 27 that constructs its own texts around continuous distinctions and branching relationships with open interchanges, as a network-like web particularly characterized by the fact that its wealth of information and ability to learn are not conclusively determined by its initial assumptions and distinctions. This likewise involves a greater sensitivity to situations involving incomplete information, the meaning of uncertainty, ignorance, and the unforeseeable effects of the discontinuous evolution of science itself. ${ }^{28}$ Such a mode of thought, such a mode of writing, must now provide a template for legal theory, as well.

24 B. Groys, On the New (2014) 184.

25 Luhmann (fn. 12) 122, 147 (knowledge as a free-flowing quality of expectation).

26 Cf. Luhmann (fn. 6) 106; A. Nassehi, Der soziologische Diskurs der Moderne (2006) 275 (with regard to consciousness).

27 Ladeur (fn. 20) 37; cf. Luhmann (fn. 6) 30 f.; J. Clam, Was heißt, sich an Differenz statt an Identität zu orientieren? (2002) 40 f.; cf. also Lavaud-Forest (fn. 17) 55 ff., 63 ("pensée réseau").

28 Luhmann (fn. 6) 14 f.; cf. also J.-F. Lyotard, The Postmodern Condition (1984) 60. 


\section{Difference, Autopoiesis, Différance}

The realization of the impossibility of a complete and conclusive exposition of knowledge and the transition to polycontextual, "fragmentary" knowledge systems have at the same time promoted a theory of difference that may be considered exemplary of both Niklas Luhmann's systems theory and Jacques Derrida's philosophy of writing. Difference theory is also closely linked to the rise of computers and their connection to networks and is seen today both as a new model of horizontal organization and, not least, as a means of refining our ability to endure the incommensurable and heterogeneous fragmentary knowledge of our splintered contemporary culture. In systems theory, for example, the concept of the system functions not as a cipher for some higher unity of concrete phenomena that localizes truth within the whole, ${ }^{29}$ but rather as a placeholder for the process of an ongoing delimitation between the inside of a system and the outside of its respective environment. This usage of the term system is in turn linked to the two-sided form proposed in mathematician and logician George SpencerBrown's Laws of Form (1969). ${ }^{30}$ Both Luhmann and Spencer-Brown are concerned with the theory of difference as an operative theory, i.e. with conceptualizing the production of order through the drawing of boundaries in the medium of communication or of the symbolic. The two-sided form is neither given nor to be found "outside" in the world; it must be drawn, marked, outlined, instituted, or otherwise determined in practice by a user - and only in the ongoing repetition of this drawing of boundaries can it be stably maintained as the eigenstate of the inside of a system as opposed to its outside, which is subject to the flow of time and unforeseeable events.

Yet this new understanding of the concept of form as a drawing of boundaries (and no longer as a figure or shape) is explicitly linked with a written processing language that cannot be dissociated from the rise of computers or its concomitant epistemology of networks, even if both Luhmann's differential system as well as Spencer-Brown's two-sided form have at times been presented as a kind of new "ur-foundation" of thought, a new "ur-logic" of differentiation. ${ }^{31}$ Just as systems theory describes the processing of systems/differences over a historically irreversible period of time, Spencer-Brown differentiates between (produced) distinctions and (given) differences. As Louis Kauffman has rightly noted, Laws of Form is "a lucid book with a topological notation based on one symbol." 32 This means, however, that the idea of drawing boundaries, the two-sided form as a meaningful concept, presupposes a time- and space-consuming process of mapping onto a topological medium that the performative act of marking distinctions does not provide. Only when a distinction is made can form be thought of as "cleav[ing] a domain."33 In other words, the operation of drawing boundaries can become the subject of a supposedly new "ur-logic" only when a symbol (a sign, a notation) has already been marked within an appropriate medium, when the

\footnotetext{
29 Nassehi (fn. 26) 302.

30 Luhmann (fn. 6) $28 \mathrm{ff}$., 29 f. (the system as an application of this concept of a two-sided form); G. Spencer-Brown, Laws of Form [1969] (2008) 3.

31 Critical of the decontextualization of thinking in differences: Clam (fn. 27) $107 \mathrm{f}$.

32 L. H. Kauffman, "Das Prinzip der Unterscheidung" (2005) 173 ff., 174.

33 Kauffman, ibid. 174, 173.
} 
process of marking has already been transformed into the "rigidity" of the sign and the distinction can be read one-to-one in an ongoing (repeating, recursive) movement, as in a computer. The two-sided form, as form, is contingent on the mediality of the medium, which is not available to the act of distinction itself but rather must be presupposed as the other of form, as its unmarked space. ${ }^{34}$ And precisely because it is a two-sided form, it turns out to be - here one can only agree with Dirk Baecker - the "cultural form of the computer." 35

Luhmann's theory of social systems is also partly a reaction to the binary functioning of computers. The social system is conceived as an autopoietic communications system. As such, it does not limit its system formation process to structure building (self-organization) independent of communicative events. Rather, through the ceaseless exchange of all system components - of structures and operations - it constructs a dynamically stable "implementation-only structure" 36 that remains bound to the "recursiveness of events" 37 but not to their presence. Via this recursive network-like structure, the social system institutionalizes the regular prospect of communication connections, though it is a prospect which cannot hide the fact that in the transition from structure to operation there is always an uncertainty that must be overcome, one which is beyond mechanical redundancies and cannot be controlled either by or within the system. Social communications systems are autopoietic in the sense that they construct invariants of meaning in the practice of communications and speech communities through corresponding repetition frequencies (redundancies) and are then able to stabilize these invariants for further use as "intrinsic values." But the system operates as a non-trivial machine and thus cannot simply "deduce" new communications from linguistic structures. It can only make the result of a past communication into the basis of a new communication in the present, i.e. it can only ever create a condensed space of possibility "in which [a] new operation 'happens." 38 Luhmann's starting point for describing this point of rupture in the continuity of the system-internal stream of speech is the double concept of "condensation" and "confirmation" first articulated in Spencer-Brown's Laws of Form. Luhmann, however, much more strongly than mathematics generally (and perhaps also more strongly than Spencer-Brown), insists on the distinctness of the repeating situations with which recursive communications systems are confronted. Whereas a mathematical sign, wherever it appears, always means the same thing $(A=A),{ }^{39}$ meaningful terms in social communications systems only become

34 A similar argument is provided by Stetter (fn. 3) 90 ("We can see, distinguish, identify something only to the extent that it is medially given to us"), on the basis of Nelson Goodman's theory of symbols.

35 D. Baecker, Studien zur nächsten Gesellschaft (2007) 35 (the organizing figure of teleology as the cultural form of writing, restless self-referentiality - equilibrium - as the cultural form of print).

36 Cf. Clam (fn. 27) 60; Nassehi (fn. 26) 298.

37 Nassehi, ibid. 279.

38 G. Teubner, "Self-subversive Justice" (2009) 16; H. v. Foerster, Der Anfang von Himmel und Erde hat keinen Namen (2008) 43 f. (concerning non-trivial machines).

39 J. Simon, Philosophy of the Sign (1995) 83. 
stabilized by "omitting the non-repeatable moments of different situations" (condensation) and simultaneously affirming definitions through the development of generalized "invariants of meaning" (confirmation). ${ }^{40}$ Luhmann's autopoiesis of communication thus represents an inwardly restive, nervous stability, a "dynamic order of lasting change." 41

A comparable referential context may be found in Jacques Derrida's philosophy of writing. Derrida's notion of writing as différance presents information processing as a "happening" in the world that does not want to end, a ceaseless, imperceptible, paradoxical movement that connects repetition with otherness (iterability). ${ }^{42}$ Just as a network consists of an abundance of nodes, is constantly subject to further development, and thus can never be completed (nor unified, nor identical with itself), différance produces a permanent dis-placement of signs in time and space. The problem of maintaining continuity in the forms and rules of written language then turns out to offer insight into the "rudderlessness" of information in the course of its reuse. Writing generates a form of iterability in which the "identity" of information is continuously deferred and produces a perpetual rupture with its context in both a material and a temporal sense. The horizontal movements of différance emerge as a "web of differences," 43 references, and deferrals in a frameless, infinite space, as the fixation and fulfillment of a meaning that already in the next moment is again "dis-placed" and "distorted." 44 The habits and customs of writing leave behind "traces" in the network of language that cannot simply be ignored as usage continues to develop, but rather create certain necessities and compulsory connections for the future. Conversely, for Derrida there is a point at which language use experiences a moment of disturbance and openness that cannot be bound by a highest or final authority, but rather makes written language susceptible to incessant "deconstructions" in the process of its ongoing re-appropriation, thereby embedding it in an interminable dynamic of "varying repetition." 45 As in the case of Luhmann's social systems, the possibility of a notion of order is thus pushed further toward its limits (and perhaps even beyond them).

\section{The Question of the Beginning}

The history of thinking in terms of networks and differences is closely tied with a reassessment of the question of the beginning (of the cosmos, of the world, of life, of

40 Luhmann (fn. 6) 83. Elsewhere - in Die Politik der Gesellschaft (2000) 66 - Luhmann describes "the condensation of an identity by the omission of an abundance of context-dependent characteristics and the reaffirmation of this identity for entirely different situations. One could also speak here of selection and generalization."

41 G. Teubner, "Der Wahnsinn der Rechtsenzyklopädien" (2005) 587 ff., 592; Clam (fn. 27) 55 (on the "endogenization, so to speak, of the most restless variables and their integration into operative recursions").

42 J. Derrida, Margins of Philosophy (1982) 315; cf. also S. Weber, Benjamin's-abilities (2008) $5 \mathrm{f} ., 122$ (on iterability as the center of différance).

43 Derrida (fn. 42) 12.

44 Derrida, ibid. $307 \mathrm{ff}$.

45 B. Waldenfels, Schattenrisse der Moral (2006) 137. "Repetition is a form of change," as Brian Eno (formerly of Roxy Music) has described this paradox, which is already reflected in the Talmud. Cf. J. Faur, Golden Doves with Silver Dots (1999). 
human beings, of culture, of language, of knowledge, etc.). The need for such a reassessment became clear, at the latest, in the early twentieth century. Husserl's Lectures on the Phenomenology of the Consciousness of Internal Time (1905-1910) showed that a beginning, an "adumbrating continuity" of consciousness, which experiences time as a sequence of events occurring in the present while continuously nourishing itself on retentions and protentions, cannot be accounted for phenomenologically. ${ }^{46}$ Language theorists of the 1920 s and 30s likewise quickly came to realize that the question of the origins of language ultimately could not be answered. ${ }^{47}$ Roughly half a century later, the philosopher Hans Blumenberg articulated a similar reservation: "To speak of beginnings is always to be suspected of a mania for returning to origins," and to run the risk of dissolving the Other of man in a kind of "omnipotence of wishes." 48 This does not simply push the question of the beginning aside, but it does qualify it as in a certain sense unsolvable. This motif of the loss of a beginning whose lack of difference guarantees a more or less absolute certainty finds its way into Jan Assmann's theory of cultural memory insofar as such memory is primarily interested not in historical facts or their appearance as such, but in the discontinuous currents of traditional knowledge about historically relevant events, symbols, buildings, landscapes, texts, etc. ${ }^{49}$ Botho Strauss has spoken in this context of a "moribund beginning," which he gives the literary form of an interconnection of mental leaps in Beginnlosigkeit (1992). The fragments of this small book are linked only by the thin thread of the experience of the "incomprehensible," the shocking realization "that there is no first and last, neither beginning nor end, neither root nor ground." 50

The motif of a "beginninglessness" with no solid ground beneath its feet has in recent years also developed a penetrative power in the fields of biology, cybernetics, systems theory, and theory of writing. The notion of un-asking the question of the beginning has perhaps been articulated most poignantly in the work of cognitive biologists Humberto R. Maturana and Francisco J. Varela, ${ }^{51}$ who in the $1970 \mathrm{~s}$ developed the idea of the autopoiesis or self-production of life, crediting the preservation of the unity of life to a purely system-internal dynamic, a circular, self-organized complexity posited as the difference between life and non-life.52 Brian Arthur has followed up on this concept with his recent thoughts on technology as a collective,

\footnotetext{
46 Cf. Nassehi (fn. 26) 298.

47 Cf. W. Benjamin, Probleme der Sprachsoziologie [1936] (1991) 453 (with a quote from Delacroix: "The problem must be deferred").

48 H. Blumenberg, Work on Myth (1988) 21.

49 Cf. J. Assmann, The Price of Monotheism (2009) 91 ("Rather than asking how it actually happened, it asks how and why it was remembered"). One would thus have to relativize the proposition, passed down from Alexis de Tocqueville to Carl Schmitt, that in order to grasp the forces of history, one must understand things at "the moment of their emergence," as any such "emergence" must establish a tradition - and this can only be understood ex post facto.

50 Botho Strauss' "bottomless beginninglessness" in a way brings to mind Thomas Mann's Joseph und seine Brüder (1933), cf. J. Assmann, Thomas Mann und Ägypten (2006) 29 ff.

51 Cf. N. Luhmann, A Systems Theory of Religion (2013) $154 \mathrm{f}$.

52 H. R. Maturana/F. J. Varela, Autopoiesis and Cognition (1980) 9.
} 
self-generating evolutionary process that has always already begun. ${ }^{53}$ Ranulph Glanville articulates a similar idea in the field of cybernetics: the act of differentiating always implies a further differentiation, ${ }^{54}$ so that what is presumed to be the final differentiation never is. In Heinz von Foerster's second-order cybernetics, as well, the question of the beginning is considered one of the fundamentally "unanswerable, undecidable questions." 55 Luhmann's autopoietic communications system likewise operates in the context of a self-relation, reproducing itself with the help of those operations it itself produces; the question of how changes come to be must be answered "in terms not of 'beginnings' but of differences." 56 Even Derrida's thoughts on the "trace" can be interpreted in this way: the trace refers back to an impossible (insignificant) origin to which the trace does not have access, but which - in the impossibility of its being present - is already contained in the form of the process of signification. ${ }^{57}$

These considerations suggest a re-evaluation of the question of the beginning. Even if it might seem doubtful that the question of the beginning could be replaced by a kind of unfathomable beginninglessness, ${ }^{58}$ yet it cannot be denied that one "immediately engages in logical somersaults" as soon as one asks the question "of the beginnings before the beginnings." 59 In contrast to the culture and epistemology of printing, where the handling of distinctions could still be attributed to the "pure" thinking of an author hiding behind the sensory representation of thoughts, there is in any inquiry into the beginning a "trace" of the culture and epistemology of networks. This situation must in any case lead to a new division of labor among the scientific disciplines or, if nothing else, to a different way of linking systematic and evolutionary theories. Because every theory, considered systematically, runs up against undecidabilities that manifest themselves in tautologies and (foundational) paradoxes, increasing weight is given to evolutionary theories that do not reduce innovations to causal explanations. This is at least the case in the context of the humanities. In the hard sciences, evolutionary theory - to the extent that it draws on Darwin - addresses the question of the beginning with recourse to the threefold model of variation, selection, and restabilization, and still comes to favor differences over origins. Responsibility for the question of the beginning thus ultimately devolves to modern physics. But here, too, it can be answered only if one holds on to the idea of a unified description of the world and the cosmos - as do, for example, quantum cosmologists - and continues to search for a "theory of everything" that could take the competing concepts of time in the fields of gravitational theory and quantum physics, incompatible since the days of Albert

53 W. B. Arthur, The Nature of Technology (2009) 167; cf. Rheinberger (fn. 13) 125 re epistemology ("Scientific objects are always already transformations of formerly scientific objects").

54 R. Glanville, Objekte (1988) 172.

55 v. Foerster (fn. 38) 29.

56 Luhmann (fn. 12) 561, see also $592 \mathrm{f}$.

57 In a historico-philosophical context, cf. G. Agamben, The Time That Remains (2005) 103; S. Kofman, Derrida lesen (1987) 57.

58 Re more recent "countermovements" that give theoretical weight to "events" or "truthevents" that demand "our fidelity," cf. A. Badiou, "The Three Negations" (2008) $1877 \mathrm{ff}$.

59 v. Foerster (fn. 38) 29. 
Einstein and Werner Heisenberg, and successfully bring them together in a conflated form (or Big Bang).

\section{New Relationship Between the Human and Natural Sciences}

The growing importance of questions of evolution (of human beings, of language, of knowledge, of culture, etc.) in the humanities has led conversely to the increasing significance of cultural and medial questions in the natural sciences. ${ }^{60}$ As a result, the borders between the human and natural sciences have become much more porous. The concept of information that first emerged in the context of cybernetics (Norbert Wiener, Claude E. Shannon), retroactively applied to the explication of genetic processes - of "genetic information" - is the basis for central aspects of Ernst Mayr's Animal Species and Evolution (1963), not least Mayr's notion of an "open" program for the adaptation of collective symbolic orders, developed in the final section titled "Man as a Biological Species."61 New theories of cultural evolution have drawn on Mayr's work, at least indirectly, insofar as they consider the biological-genetic components and the social (cultural) components of the human species to be mutually responsive. Accordingly, Merlin Donald understands evolutionary psychology as a biocultural theory that views the evolution of the human mind as resulting from the evolution of cognitive communities whose capabilities are in turn associated with the evolution of the expanding use of signs (mimicry, gesture, speech, writing). ${ }^{62}$ This even makes it possible to link a theory of law conceived in terms of media theory with recent deliberations on the theory of the subject in the context of evolutionary psychology, which combines an anthropology oriented toward historical universals with the notion of human beings' "evolving psychological architecture." 63 This shifts the emphasis of the concept of cognition and knowledge even further in the direction of culture and media and connects subjective knowledge in general with the emergence of a "cognitive-cultural system."64 The traditional conceptual distinction between culture (as a set of shared attitudes, customs, linguistic signs, habits, etc.) and cognition is thereby relativized and replaced by the supposition that any given cultural order must itself be conceived as a "gigantic cognitive web, defining and constraining the parameters of memory, knowledge, and thought in its members, both as individuals and as a group." 65

Modern scientific theories consider human consciousness, mental development, ways of thinking, and worldviews, along with all forms of the individuality of the subject, to

60 Cf. T. Winograd/F. Flores, Understanding Computers and Cognition (1986) $64 \mathrm{f}$. ("recurrence"); Barabási (fn. 11); J. Tooby/L. Cosmides, The Psychological Foundations of Culture (1992); P. J. Richerson/R. Boyd, Not by Genes Alone (2005); M. Tomasello, Origins of Human Communication (2008); M. Donald, A Mind so Rare (2001). One could also mention names like John Brockman, Jared Diamond, Steven Mithen etc.

61 E. Mayr, Populations, Species, and Evolution (1963) 375 ff. (cited from the abridged version); on how the production of discourse, cybernetics, and information theory have constituted the genetic code, cf. L. E. Kay, Who Wrote the Book of Life? (2000) $73 \mathrm{ff}$.

62 Donald (fn. 60) 252, 260; from a legal theory perspective: Ladeur (fn. 13) 118.

63 Cf. Tooby/Cosmides (fn. 60) 89.

64 Donald (fn. 60) xiv (Prologue).

65 Donald ibid. 
be contingent from the outset on cultural formations. The natural sciences thereby propose an impersonal, anonymous dynamic of cultural change. Consciousness is always already linked to a "society of mind" (M. L. Minsky) and, like the divided subject of Lacanian psychology, is reliant on a "big Other," the splintered universality of the symbolic (or cultural) order. ${ }^{66}$ The traditional separation between the hard sciences and the humanities is thus further undermined, opening new fascinating possibilities of intellectual dialogue between the two fields in the future.

The rise of computers and, in their wake, modern cognitive science, completed the conceptual unification of the mental and physical worlds by showing how physical systems can embody information and meaning. The design and construction of artificial computational systems is only a few decades old, but already such systems can parallel in a modest way cognitive processes - such as reason, memory, knowledge, skill, judgement, choice, purpose, problemsolving, foresight, and language - that had supposedly made mind a metaphysical realm forever separated from the physical realm, and humans metaphysically disconnected from the causal network that linked together the rest of the universe. ${ }^{67}$

Even those who consider equating natural and artificial intelligence to be an exaggeration can scarcely deny that, with the rise of computers and the epistemology of networks, in which the drawing of boundaries necessarily entails their transgression, a return to the separation of the humanities and hard sciences in the style of the nineteenth century is no longer possible. If my impression is not mistaken, it is currently the humanities above all that must come to better understand this.

\section{FURTHER CONSEQUENCES FOR LEGAL THEORY}

\section{The Rise of Practical Knowledge}

While the relationship between theoretical and practical knowledge in the European tradition was normally conceived as a hierarchy, as the primacy of obtaining knowledge over acting, and moral philosophy after Kant was long oriented toward theoretical philosophy, ${ }^{68}$ contemporary debates have been defined by the rise or "rediscovery" of practical knowledge. Beginning with the linguistic turn in philosophy and the increasing prevalence of electronic media such as film and radio, a growing number of different scientific disciplines have incorporated a pragmatic component that has led to a reassessment of the relationship between theory and practice. ${ }^{69}$ In the realm of linguistics, one may point to Karl Bühler's theory of language, which features the beginnings of a revaluation of language's pragmatic aspects as opposed to its function

\footnotetext{
66 S. Žižek, How to Read Lacan (2006) 9, 11-12, 27 ff.

67 Tooby/Cosmides (fn. 60) 20.

68 For the tension between Aristotelian ethics and (Neo-)Kantian moral philosophy cf. Waldenfels (fn. 45) 13, 84 ff.; H. Krämer, Integrative Ethik (1992) 95.

69 Cf. M. Sandbothe, Pragmatic Media Philosophy (2005) 33 ff. This turn toward pragmatism has its precursor in, e.g., Baumgarten's revaluation of sensory perception in the context of modern aesthetics.
} 
as a conveyor of meaning, relativizing its "representational function" in favor of its "expressive and conative functions."70 In Wittgenstein's later philosophy, the relationship between semantics and pragmatics is completely turned around. Linguistic analysis is no longer centered on theories of representation, of describing the relationship between signs and signified objects; rather, Wittgenstein understands the semantic capacity of language entirely in terms of usage. ${ }^{71}$ In particular, Wittgenstein's phenomenology of the rule is designed to show that language and grammar are invariably tied to habitual usage in practice, i.e. to established regularities and conventions in dealing with words and sentences. At the same time, Wittgenstein emphasizes that usage is inextricably linked with non-linguistic operations, with habits, customs, institutions, and other "forms of life"72 that embed the individual and his speech in a collective order, thus allowing for the development and reproduction of culture. In post-structuralist literary criticism and legal theory, this corresponds - with a stronger emphasis on the significance of the medium of writing - to an "ethics of reading" which follows an interpretive imperative that emerges from practice and "reads" from this practice the task of maintaining a pluralism and diversity of forms of life. ${ }^{73}$

Increased significance given to the functional imperatives of practical knowledge as opposed to the homogenizing "normalizations" demanded by theoretical knowledge may be observed not only in linguistic theory, philosophy of language, and poststructuralism, but also in (post-)analytical philosophy and philosophy of science. Since the early twentieth century, these latter have broken with the idea that there can exist explicit knowledge without recourse to implicit knowledge. Even strict scientific knowledge, which requires the existence of writing and printing, is recognized here as being dependent on the collective knowledge of regional scientific cultures, on a "style of thinking" to which an experimental researcher must have access if he is to be able to enrich his abstract knowledge with forms of personal "experience." ${ }^{\prime 4}$ In a kind of early culmination of this line of thought, Gilbert Ryle in The Concept of Mind (1949) fights back against the Cartesian myth of the "ghost in the machine," according to which mental operations do nothing but administer theoretical knowledge. Against this "intellectualistic legend" Ryle proposes a distinction between ability and knowledge, between knowing how and knowing that, and thus arrives at the insight that a successful

70 Bühler (fn. 10) 37 (Bühler explicitly writes of a "speech situation"); B. Waldenfels, Bruchlinien der Erfahrung (2002) 109; for a corresponding line of thought in the theory of science (Ian Hacking et al.) cf. Rheinberger (fn. 13) $79 \mathrm{ff}$.

71 Cf. L. Wittgenstein, Philosophical Investigations (2001) § 43 (“... the meaning of a word is its use in the language"); for more detail see Stetter (fn. 2) $515 \mathrm{ff}$.

72 Cf. Wittgenstein (fn. 71) $\S \S 199,201,202,23$ ("life-form"); V. Descombes, The Mind's Provision (2001) 126 f., 227; B. Waldenfels, In den Netzen der Lebenswelt (1985) 85; from a legal theory perspective: K.-H. Ladeur, Der Staat gegen die Gesellschaft (2006) 2 f., 70 ff.

73 Cf. I. Augsberg, "Rechtslektionen" (2009) 71 ff., 82 f., 94 (with reference to Joseph Hillis Miller, The Ethics of Reading, 1987).

74 Rheinberger (fn. 13) 61 f., 120; concerning the concept of a "style of thinking" (Denkstil), a term presumably coined by Ludwik Fleck, cf. also v. Foerster (fn. 38) 188. 
practice anticipates its own theory. ${ }^{75}$ Michael Polanyi's philosophy of science supplements this distinction between ability and knowledge with the important insight that knowledge always contains an implicit element, what Polanyi calls the "tacit component" or "tacit dimension" of knowledge. ${ }^{76}$ Such tacit knowledge corresponds to a vaguely defined "subsidiary awareness" that precedes the "focal awareness" of explicit knowledge; Polanyi's theoretical framework thus precludes the illusion that knowledge can ever be fully articulated. ${ }^{77}$ A mathematician may develop a mathematical theory about the behavior of frogs only if he already knows what a frog is. The notion of what a frog is, however hazy and ill-defined, must be presupposed as existing within an interpretive community and must have already been conveyed to the regional scientific culture that is mathematics, but the idea of the frog itself cannot be the product of theoretical explication. ${ }^{78}$

Michael Oakeshott's (political) philosophy is likewise defined by this understanding of knowledge as anchored in historically evolving modalities. In his very first book Experience and its Modes (1933), Oakeshott describes a pluralistic modal epistemology that characterizes knowledge as being contingent rather than rooted in a certain principle. Scientific, logical, economic, and historical knowledge all represent modalities of experience, interwoven with local experiential knowledge; it is never the case that rationalism alone produces "true" statements about the world. ${ }^{79}$ In economics and theories of economic order, this revaluation of practical knowledge finds perhaps its most poignant expression in the work of Friedrich August von Hayek, who describes the market as a "process of discovery" in which relevant knowledge is dispersed among a large number of individuals. Knowledge is thus understood as something that is mediated by groups or organizations and, from a cognitivist perspective, is ultimately linked back to the impersonal, highly-aggregated communications network of the market, rather than gathered in a personal subject with superior knowledge. ${ }^{80}$ In the field of practical psychology, Hans Krämer's Integrative Ethics (1992) outlines a post-teleological "ethics of striving" (Strebensethik) with an emphasis on practical intelligence, drawing on older conceptions of phronesis and prudentia, psychic topography and rhetorical plausibility, and defining these against an "ethics of

75 Cf. G. Ryle, The Concept of Mind [1949] (2000) 25 ff.; Stetter (fn. 2) 70; Waldenfels (fn. 72) 85 f.; L. Heidbrink, Kritik der Verantwortung (2003) 313.

76 M. Polanyi, Personal Knowledge [1958] (1974) 69 ff.; id. (fn. 19); cf. also Gill (fn. 19)

51 ff.; Stetter (fn. 3) 111 ff.; Rheinberger (fn. 13) 61 ff.

77 Rheinberger, ibid. 62, 63 (Citation), 98; Ladeur (fn. 17) 135, 137.

78 Cf. Polanyi (fn. 19) 6 f., $20 \mathrm{f}$.

79 M. Oakeshott, Experience and its Modes [1933] (2002) 247; I. Tregenza, Michael Oakeshott on Hobbes (2003) 21 ff.; cf. also T. Nardin, The Philosophy of Michael Oakshott (2001) in particular $194 \mathrm{ff}$. (on the close connection between practical knowledge and the rule of law in Oakeshott).

80 Cf. F. v. Hayek, "Competition as a Discovery Procedure" (2014) 304 ff.; from a legal theory perspective: Ladeur (fn. 13) 115 ff.; D. Wielsch, Zugangsregeln (2008) 82 ff., 87; cf. also P. Rosanvallon, Democratic Legitimacy (2011) 112. 
ought-to" (Sollensethik) that takes the form of strict laws. ${ }^{81}$ Emmanuel Lévinas summarizes this primacy of ethics over ontology in the proposition that "truth presupposes justice." 82 Justice here, however, refers not to formal equality, but to justice toward the Other. Its aim is a practical philosophy that is directed against the ontological normalization of things, i.e. that is concerned with preserving difference in the sense of the primordial diversity of the real, which is rooted in a meta-ethical plane - in the spoken word, in the assertion of claims, in the face and countenance of the incomparable Other. ${ }^{83}$

\section{The Network: Paradigm of a New Legal Culture}

The rigid, deductive, comprehensive rationality of moral philosophy since Kant has been displaced by a flexible, inductive web of multiple rationalities that point to the functional imperatives of the practices of a complex and highly-differentiated society. Largely in accordance with what we have described above with respect to the emergence of a new culture and epistemology of networks, the moral order is no longer thought of as something ready-made, packaged in an unconditional imperative, but rather is conceived in terms of a more situational and practice-oriented morality that is continuously updated and constantly changing in terms of the communities that interpret it and the contexts in which it is applied. Similarly, modern political philosophy sees political communities as being inserted into an inevitable process of differentiation, in which the community in question becomes "unrepresentable" and "impossible." 84 Finally, the new culture and epistemology of the network has also become central to legal theory debates. Sounding out, searching, and experimenting in an environment that never comes to rest; operating with and in the form of collateral correlations; in short, a flexible "bazaar style" has supplanted the rigid "cathedral mode" of the epistemology of print culture together with its one-point perspective. ${ }^{85}$ The supposed certainties obtained by deducing ideas from or subsuming them under a stable law has come to be replaced by the uncertainty of searching for connections, the notion of a concept of law that litigates a dynamic stability in the context of the irreversibility of historical time, the paradoxical movement of "varying repetition."

81 H. Krämer (fn. 68) 95, 127 ff., 168 ff.; see also Waldenfels (fn. 45) 218 ff.; a similar concept of a "contextualized moral of action" has been described by Heidbrink (fn. 75) 49 ff., 313; cf. also id., Handeln in der Ungewissheit (2007) $105 \mathrm{f}$.

82 E. Lévinas, Totality and Infinity (1969) 90 ("la vérité suppose la justice"). This motif is also taken up in Bernhard Waldenfels' "responsive ethics." See B. Waldenfels, Antwortregister (1994) $311 \mathrm{f.}, 560 \mathrm{ff}$.

83 E. Goodman-Thau, Aufstand der Wasser (2002) 252 ff., 263; Waldenfels (fn. 22 Phenomenology) 74.

84 J.-L. Nancy, The Confronted Community (2003) 23 ("What is coming upon us is an exhaustion of the thought defined by the One."); id., The Confronted Community (2009) 19 ff., $23 \mathrm{ff}$. (on the unrepresentable, "inoperative" community); R. Esposito, Communitas (2010) 76 ("To say that the community is impossible means in fact that that impossibility is community"); cf. also Guéhenno (fn. 11) 33.

85 E. S. Raymond, The Cathedral and the Bazaar (2001) 19 ff. (on metaphors of open source-technology). 
The theory of law developed by Karl-Heinz Ladeur, whose 1992 Postmoderne Rechtstheorie already begins to experiment with the concept of the network, ${ }^{86}$ exemplifies this understanding of the network-like auto-stabilization of the law through diverse "relational" connections. In a 1995 publication Ladeur explicitly ties legal theory to the idea of "thinking in networks." 87 A more recent work (2006) tests this "thinking in networks" with respect to government decision-making (the new logic of intra- and inter-organizational networking). ${ }^{88}$ Botho Strauss, in his novella Die Unbeholfenen (2007), attests that the concept of the network, given its ubiquity as well as its apparently universal applications in conceptualizing the most diverse phenomena (from terrorist groups to the human brain), runs the risk of being both a key and a cage, a new "prison of the mind," and this danger cannot be ruled out in the context of discussions of jurisprudence. For the theory of law, then, it seems all the more necessary to link the network, as Ladeur does, with the new epistemological situation of "computer culture," 89 what we have here called the culture and epistemology of networks. The network would then not be a new prefabricated component for understanding legal theory, nor some new jurisprudential grab bag, and certainly not a new "universal concept of law," but rather the most succinct expression of a form of "thinking in heterarchical linkages that observes the connectivity of components and seeks to identify their dynamic patterns." 90 A network theory of law would thus be concerned not only with conceptualizing the density and complexity of the linkages among legal positions, but also and especially with defining the network in contrast to the top-down logic of the systematic legal thought of the nineteenth century, the stable conceptual hierarchies of a print culture whose systems institutionalize the suggestion that they already contain the answers to all possible questions.

Understood this way, the network would subsequently also have to function as a conceptual model for the idea of the system itself. Today the legal system can only be understood as a polycentric, polycontextual web of differences whose individual pieces comprise a "unit" only in the form of temporary linkages among neighboring components. In this respect, medial theory of law also deviates from Niklas Luhmann's systems theory. Though Luhmann is indeed responsive to the new strategic and situational logic of networks, as when he describes the internal workings of the autopoietic legal system as being oriented toward the "preservation of difference" rather than the "preservation of its existence,"91 his conception of networks -

86 Cf. e.g. Ladeur (fn. 22) 42 ("Every act of speaking about something must draw on a network of meaning-generating relationships between language and the world.").

87 Ladeur (fn. 20) 37; cf. also M. E. Katsh, Law in a Digital World (1995) 21 ff. (law as a "seamless web").

88 Ladeur (fn. 72) $296 \mathrm{f}$.

89 K.-H. Ladeur, "Computerkultur und Evolution der Methodendiskussion in der Rechtswissenschaft" (1988) $218 \mathrm{ff}$.

90 K.-H. Ladeur/T. Vesting, "Geistiges Eigentum im Netzwerk" (2008) 123 ff., 135. Cf. also A. Koschorke et al., Der fiktive Staat (2007) 386, and I. Augsberg, "Das Gespinst des Rechts" (2007) $479 \mathrm{ff}$. (both with reference to the necessarily epistemological alignment of the concept of networks).

91 N. Luhmann, Organisation und Entscheidung (2000) 55; cf. also id., Law as a Social System (2004) $157 \mathrm{f}$. 
proceeding from his experiences in organizational sociology - is strongly associated with notions of trust as developed through a kind of recurrent probation. 92 This line of thought has been taken up by other legal theorists such as Gunther Teubner, who conceives of the network as a form of "generalized reciprocity," a mechanism that spontaneously creates order, in contrast to the competitive behavior of markets. ${ }^{93}$ The network is thus understood as merely a counter-institution for the differentiation of autonomous functional systems, as the "transboundary linkage of autonomous logics," 94 but not as the possibility of a transformation of systems theory or the concept of the system itself. From a media theory/legal theory perspective, by contrast, the point is precisely to strengthen the idea of the network as a new model for developing a legal order without a stable framework or rigid boundaries, a constellation that as a whole necessarily remains obscure, "no longer a finished corpus of writing, some content enclosed in a book or its margins, but a differential network, a fabric of traces referring endlessly to something other than itself, to other differential traces." 95

In any case, merely supplementing systems theory with a kind of network analysis, the latter understood in terms of transboundary linkages, is not sufficient to adjust legal theory to the new conditions of network culture. With the switch to fluid combinatorial networks as a form of organization - one could also speak of an "unstable dialectic," to use William J. T. Mitchell's term ${ }^{96}$ - the ways in which boundaries are drawn have also changed, as has the construction of boundaries themselves. Even under network conditions the boundaries of law do not disappear entirely, since the network presupposes print culture and its accompanying body of laws, which still provide for relatively clear relationships among many legal sectors today. However, law is now confronted with a new dynamic of open, crossed, and blurred boundaries, the loss of a secure framework, the fraying of borders that "no longer appear to be guaranteed by a certain number of established criteria." 97 Faced with this dynamic, law cannot close itself off by relying on its current operations, as it is assumed to do in Luhmann's theory of the operational (normative) closure of the legal system. ${ }^{98}$ All in all, it thus seems highly doubtful that the idea of the system with its two-sided logic (system or environment) is suited to the new epistemology of networks at all, particularly since systems theory, with "system" referring to the inside of the form, favors a concept that cannot be fully divorced from the tradition of organological thought and has been

92 Cf. only Luhmann (fn. 91 - Organisation) 385 f., 408 ff.; G. Teubner, Networks as Connected Contracts (2011) 98 f., 171-2.

93 Teubner (fn. 92) 170 ff.; see also Wielsch (fn. 80) 192 ff. (from a cognitivist perspective).

94 A. Fischer-Lescano/G. Teubner, Regime-Kollisionen (2006) 59.

95 J. Derrida, Parages (2011) 110; Augsberg (fn. 73) 92; on experimenting with this new form of the edge, the boundary, or the frame as an "open interface" on the analogous level of the "fragmented body," cf. also R. Esposito, Immunitas (2011) 151; J.-L. Nancy, Corpus (2008) 107.

96 F. Steinhauer, "Bildkontakt" (2009) 61 ff., 64 (with reference to W. J. T. Mitchell, Picture Theory (1994).

97 J. Derrida, Préjugés (2005) 33.

98 Luhmann (fn. 91 - Law as a Social System) 106 ff.; critically in K.-H. Ladeur, "The Postmodern Condition of Law and Societal 'Management of Rules"' (2006) $87 \mathrm{ff}$. (on the normative power of practical experience); L. Leyesdorff, "Scientific Communication and Cognitive Codification" (2007) 375 ff., 383 (for the example of science). 
employed by Kant, Hegel, Savigny, Puchta and others to describe and construct a hierarchical body of laws. Unless all indications are deceiving, the high point of this tradition's self-evidence lies behind it. At the least, the system/environment distinction will in the future no longer be able to assume a central place from which the consistency of legal theory - in the sense of its being "fitted" to other distinctions - can be organized.

\section{Justification of the Validity of Law and Practical Legal Culture}

The new culture of networks has driven law into the infinite loop of an unceasing deferral, an endless search for itself in the connectionist (recursive, relational) patterns of its own practice. On the one hand, the always already prevailing "occurrence" of positive law's continuing development, the constant amending and transforming of laws, directs jurisprudence toward the legacy of its own past. But just as von-Neumannmachines operate on the logic of self-modifying programs through the non-hierarchical feedback of commands and data with unpredictable (at times undesired) results, ${ }^{99}$ the ongoing search for sustainable connections under network conditions - in contracts, in the passing of legislation, in court verdicts, in mediation and arbitration, in legal doctrines and legal theory - also opens up new, unforeseeable possibilities for legal innovation. In the process, law must always (re-)produce its own certainties anew and within a certain proximity to the "constraints of legal practice." Derrida has described both of these phenomena, the contingency of law and at the same time its inherent search for justice, and in Force of Law (1991) defines justice as that which cannot be calculated, programmed, or anticipated, an unrepresentable, transcendent "event" that is never fully present. ${ }^{100}$ Gunther Teubner similarly links these two aspects of contemporary legal practice with the "paradox of law," i.e. with law's logical self-reflexivity along with its resulting obstructive effects as well as potential un-obstruction, the paralysis to which paradox leads along with the necessity of escaping said paralysis, using paradox as an opportunity for the potential de-paradoxification of the law, for the continuous "self-subversion" of law and justice. ${ }^{101}$

To the extent that a fluid combinatorial network of differences leaves the legal order in a permanent state of inner ("paradoxical") turmoil, legal theory must also reconsider how it formulates hypotheses about law's origins and must avoid overloaded concepts of primordial new beginnings (ur-foundation, inception, creatio ex nihilo, etc.) that in the European tradition often carry with them strong theological legacies. Rather than assume the existence of some sacred original force and the "gesture" of its foundational

\footnotetext{
99 F. Kittler, "Protected Mode" (1997) 156 ff., 160 (in the context of the difference of real mode and protected mode).

100 J. Derrida, Force of Law (1990) 963 ff., 969 f. "Advenir" thus means not "being” but rather arriving at a non-programmable future, a kind of "messianism" that keeps the future open to the Other of law, should it ever come. Derrida also speaks here of an "ethics of hospitality." Cf. G. Vattimo, "Historicity and Différance" (2007) 131 ff., 137 f.

101 Teubner (fn. 38) 17, 19; id., "Dealing with Paradoxes of Law" (2006) $41 \mathrm{f}$.
} 
power, ${ }^{102}$ Luhmann posits a legal system that knows no beginning. The legal system must have always already begun in order to be able to read actions and events in its environment with reference to its own expectations. ${ }^{103}$ Legal practice is always connected to already existing legal traditions; the determination of a tradition's origin is thus necessarily a myth produced within the system itself, though one that in its fictionality certainly merits attention. ${ }^{104}$ It is precisely in this sense that Derrida's Préjugés (1992) - partly in remembrance of Freud's theory of the birth of law out of the prohibition against incest and murder - links the origin of law to a "fictional narrativity," to the necessity of the "fiction of a final account," in the same way that "the dead father is a story that one tells, a rumor that circulates, without author and without end, but an unavoidable and unforgettable account." 105 This kind of beginninglessness of law is also to be found in the postmodern legal theory of Karl-Heinz Ladeur, where law as a network of differences knows "no beginning and no end," 106 but stabilizes its processing in decentralized self-organizational processes, in a connectionist, "network-like" order founded on social rules and conventions that always already exist. These conventions and rules can be condensed into their own legal terminology with the help of jurisprudence or refined by political legislation and the administration of justice by the state, but law cannot be understood as a product of the formalized decisions of state-run courts or political legislation apart from the practical rules and conventions that are rooted in (private law) society. ${ }^{107}$

Hence the notion that all justifications of the validity of law are "groundless." The ultimate basis of law is "by definition unfounded." 108 Whereas Kelsen's Pure Theory of Law sought - perhaps for the last time - a conceptual alternative to this groundlessness (but, tellingly, was able to find one only in the basic norm, which was later appropriately deemed a mere "conceptual contrivance"), today the validity and authority of law is founded in an ever-temporary linking of differences - justice/injustice that can be traced back neither to a symbol nor to a concept (a reasoning, a sense of fairness, a norm). Law rests on a diffuse (center-less) rationality that manages human relationships in terms of rules, thereby asserting a common good that "cannot be

102 This is the vocabulary used by A. Badiou, Saint Paul (2003) 6, 108 (The "truth-event" is in its universality purely subjective, singular, not subject to the hegemony of abstract homogenization.).

103 Luhmann (fn. 91 - Law as a Social System) 91 ("Legal practice always operates with a law that has historically always been there because it could not otherwise entertain the notion of distinguishing itself as legal practice").

104 Luhmann, ibid. 153; id. (fn. 6) 266; for a case study see M. Meltzer, Secular Revelations (2005) (on the constitution of the United States of America); M. Th. Fögen, Das Lied vom Gesetz (2007) 53, 57 ff. (Roman Law of the Twelve Tables); K. Robb, Literacy and Paideia in Ancient Greece (1994) 125 ff. (Draco und Solon's law-making as a myth of traditional ancient rules).

105 Derrida (fn. 97) 56, 71, 56.

106 K.-H. Ladeur, "Gesetzesinterpretation, 'Richterrecht' und Konventionsbildung in kognitivistischer Perspektive” (1991) 178.

107 Ladeur (fn. 72) $71 \mathrm{f}$; cf. also Steinhauer (fn. 96) $61 \mathrm{ff} ., 91 \mathrm{f}$. (the example of the right of personality).

108 Derrida (fn. 100) 943. 
reduced to something of its own or integrated into a whole." 109 The fluid combinatorial network of law thus inevitably reveals another side of itself that cannot be controlled by law itself, the possibility of ever-recurring ruptures, breaks and uncertainties in the ongoing process of law's "justification." 110 This is apparent, for example, in the process of linking together legal expectations (structure) and legal communications (operation) in Luhmann's autopoietic system of law, a transition that necessarily points to a discontinuity, marked by the concept of the decision, that eludes control by the system. ${ }^{111}$ Yet to refer to what Derrida calls different or other, what cannot be said to adhere to the rules at the moment of legal decision-making, ${ }^{112}$ is also to point out that the legal order, like every order, seems to produce along with itself something extra-ordinary, a foreign element, a third term "that belongs to the legal order while eluding it."113 Particularly elusive, as Legal Theory and the Media of Law shall demonstrate, is the validity and binding force of the legal order itself. This force cannot simply be produced from within the same legal system. Rather, the notion of law's "binding character" points to the shared knowledge of a practical culture and thus to the evolution of media for linguistic communication, to spoken language, writing, printed books, and computer networks, to the ruptures and displacements produced by these media in the collective orders of culture and shared knowledge, to a field that lies beyond the scope of the intentions and responsibility of the subject.

\section{Interface Management}

Any theory of law that hopes to keep up with the times must take into account the transition to an epistemology of the network. Just as the emergence of radio in the 1930s evidently led many academic disciplines to take a deeper interest in questions of the relationship between the oral and the written, today the task must be to procure an appropriate space within legal theory for the distinctive medium of our age, namely computer technology and the decentralized form of its interlinked telecommunication. If legal theory wishes to be an intellectual product of our age even into the future, it must draw upon new dynamic and connectionist forms of knowledge that exist beyond stable conceptual hierarchies. This only becomes more imperative as the new connectionist knowledge forms of the postmodern epistemology of the network point to radical changes in the structures of contemporary society that have long since been reflected in new, flexible legal forms (in civil law, public law, criminal law, etc.). A focus on media - as well as on the inextricably linked phenomena of language and shared knowledge - is thus not the product of some more or less short-lived fashion,

109 Nardin (fn. 79) 202; K.-H. Ladeur, "The Financial Market Crisis - A Case of Network Failure" (2011) 63 ff.; Waldenfels (fn. 22 - Phenomenology) 71 (citation), 81.

110 R. Wiethölter, "Recht-Fertigungen eines Gesellschafts-Rechts" (2003) 18.

111 Luhmann (fn. 91 - Law as a Social System) 84, 85, 144; Teubner (fn. 38) 15 f.

112 Cf. Derrida (fn. 100) 961 ff., 963 ff.; Teubner (fn. 101) 59 ff.

113 Waldenfels (fn. 45) 130; cf. also Waldenfels (fn. 22 - Phenomenology) 4 ("At the limits of every order, the alien emerges in the shape of something extraordinary that cannot find its place in the respective order, and, at the same time, as what is being excluded, it is not nothing"). 
but rather arises from the field itself. Law must be conceived and analyzed as a constellation of media, and this means that today every theory of law must adapt itself to media theory if it hopes to maintain its significance as theory. To borrow from the terminology of Aleida Assmann, the "function memory" of legal doctrine, which is continually being brought up to date, must be supported by an un-updated "store memory" of legal theory as media theory that expands its pool of ideas and provides legal practice with alternatives for dealing with social change. ${ }^{114}$

It would thus be wrong to want to navigate legal theory through the calm waters of its own disciplinary tradition, thereby avoiding the profound changes associated with the new culture and epistemology of the network. This must also be insisted upon with regard to the "theory of jurisprudence," which narrowly restricts itself to intradisciplinary questions of the "allocation" and "separation of powers." 115 Even if the necessity of legal theory's constant oscillation between openness and self-containment implies both its minimal engagement with non-juridical knowledge and its evercautious translation of non-juridical information into its own discipline - through which, at any rate, legal theory can only be a point of intersection for the further interdisciplinary processing of the knowledge so imported - an adequate response to the new epistemology of the network cannot consist in making what ultimately amounts to a circular appeal to a supposedly given "normativity" of the law, but rather only in allowing the knowledge pool of its own discipline to remain open to new insights, new arguments, and new ideas, i.e. in "bringing about alternative systems and spaces of representation." 116 This is imperative also because the unity of law as an academic discipline - if such a thing ever actually existed in historical reality - has long since devolved into a form of at best partially overlapping communications networks that, due to increasing specialization, tend toward a mutually reinforced self-isolation. This dynamic of self-isolation, of the creation of cartel-like "professional fraternities," must be confronted with a dynamic of openness in order to avert the threat of legal theory and its accompanying individual disciplines becoming ossified, a wholly undesirable result given the accelerated pace of cultural and social change.

That cross-border knowledge circulation is as inevitable for legal theory as it is desirable is likewise demonstrated in Hans Kelsen's Pure Theory of Law, which in many ways serves as a model for the theory of jurisprudence. Kelsen's fixation on the problem of law's validity, on a concept of norms kept separate from any practical "contamination," 117 can in fact be linked to the idea of acts of divine revelation. God's directive is substituted with an "epistemological" chain of operations in which the basic norm functions as the bearer of a final "basis of validity" in the sense of a causa prima that must be presupposed and that creates a new stable foundation which exists beyond all given certainties. ${ }^{118}$ All this was possible, however, only on the basis of a specific "analytical" scientific culture around 1900 that, particularly in Vienna, lived off its

\footnotetext{
114 Assmann (fn. 18) 123 ff., 125.

115 Cf. M. Jestaedt/O. Lepsius, Rechtswissenschaftstheorie (2008) Preface.

116 H.-J. Rheinberger, Towards a History of Epistemic Things (1997) 113 (in the context of a "pragmatogony of the real").

117 H. Kelsen, The Pure Theory of Law (1967) $3 \mathrm{ff}$.

118 Cf. Fögen (fn. 104) 91 f.; A. Schütz, "Sisyphos und das Problem" (2009) 163 ff., 168.
} 
opposition to the traditions of metaphysics and ontology, on which it therefore remained antithetically fixated. This scientific culture, into which Kelsen was socialized and to whose richness he himself contributed, found its counterpart in mathematics with David Hilbert, in logic with Rudolf Carnap, and in literature with Franz Kafka. Yet because it has long since become clear that law is more than its validity alone, that even the validity of law has its other side which eludes positive law (but which, though elusive, is not therefore insignificant), the pure theory of law today remains a legitimate object of scientific-historical research, just as the scientific culture of the Vienna Circle has become a beloved subject in the history of science. Beyond this historical interest, however, there are good reasons to doubt whether a successful updating of legal theory will ever be possible with recourse to the themes, programs, and tools of the pure theory of law alone. If Kelsen himself was the prototype of the "theory tinkerer," as Matthias Jestaedt now characterizes him, ${ }^{119}$ then what is there to prevent legal theory from tinkering with its own updates, seeking out for itself new possibilities for theoretical thought and its potential limits, rather than constantly reinstalling long out-of-date Viennese software and thereby inhibiting - or at least leaving unexploited legal theory's potential power in the present?

Against a theoretical approach that concerns itself exclusively with its own disciplinary tradition (legal theory, jurisprudence, legal history), medial theory of law advocates a program of border crossing, of making contact with the Other, of changing juridical modes of thought. "Border crossing" of course does not simply mean the abolition of borders, nor "making contact" the dissolution of divisions, nor "changing juridical modes of thought" the negation of the juridical. The point is rather to provide the study of law with new ways of understanding itself by means of different "world-images." Medial theory of law promotes a post-ontological, post-metaphysical and post-modern epistemological program, of the sort that has long influenced other disciplines such as philosophy, philosophy of science, systems theory, graphemics and literary theory. Even within legal theory, the ontological premise of the givenness of positive law has long been called into question on epistemological grounds, including by Kelsen. This question is taken up by medial theory of law, as well, although here our research program is centered not on an epistemologically founded difference between Is and Ought - as in Kelsen - but on the assumption that legal rules and values (of duty, of validity, of normativity and obligation) are fundamentally dependent on a legal culture that is bound to language and its media. Legal theory thus requires a new epistemological foundation, and available knowledge about law, its operations, its dynamics, its structures, its functions, its dependence and independence, must be expanded by new knowledge. This carries with it the consequence of subverting the still widespread distinction between cultural or social scientific (factual, descriptive) and legal (normative, prescriptive) study, which does not mean wholly denying law's status as a practical-normative field. To the contrary, medial theory of law in no way calls into question the fact that law is established within a realm of repetition, conformity, regularity, and lawfulness, one that extends into the subjectivity of the individual and in

119 Jestaedt/Lepsius (fn. 115) Introduction L. 
which social conduct according to rules first becomes at all possible, ${ }^{120}$ but rather develops this insight in a way that is appropriate to the facts of the present day. Medial theory of law hopes to contribute precisely to the project of transforming basic legal research, through legal theory, into a "universal cultural theory."

\section{Outlook}

The network as a system of order that pushes to the limit the idea of a stable form of the legal order itself can attain its fullest validity only in a particular historical period and only under certain medial circumstances and conditions of possibility. Yet the network should not be understood as an "invariant" existing beyond evolutionary discontinuities; synchronic (systematic) and diachronic (evolutionary, historical) perspectives are not absolute opposites. Just as spoken language, writing, and printed books each circumscribe particular kinds of legal knowledge and particular social (or medial) epistemologies that determine the possibilities and limitations within which law as a form of practical knowledge can be formed, the network likewise cannot be situated outside of time, history, or evolution. Thus it would not be productive to assume a historically presupposed form of law as a network and then conceptualize the evolution of law as the development of this form. On the other hand, theoretical innovations inevitably alter our view of the past, simply because the observation of history is also always an intervention into it. If, on the basis of a new culture and epistemology of networks, it can now be recognized that law is woven into a decentralized and connectionist web of differences, then this must also have repercussions for the reconstruction of historically older forms of law as well as the expertise associated with them. The aim is therefore to take the insights and concerns of a network theory of law - the constitutive role of difference, thinking in terms of heterarchical linkages, the notion of 'beginninglessness', the dependence of foundational myths on observers, the ascendancy of practical knowledge, changing ideas about the law's validity and justification, etc. - and bring them to the attention of the history of law, to test the viability of the hypotheses developed here against historical examples, in order to further develop these theoretical hypotheses themselves and at the same time demonstrate their limits.

Legal Theory and the Media of Law is not a medial history of the law. This study does not, for example, map spoken language onto oral (primitive) legal cultures in order to find out what such cultures were actually like. Nor will one find here the distancing "ethnological" view that throws a new light onto the legal culture within which we ourselves move and thereby satisfies some form of exotic curiosity. Legal Theory and the Media of Law maintains an interest in history and is in no way indifferent to historical facts, but it does not cultivate a historicist style or historicizing search for truth in the mold of Leopold von Ranke or Robin George Collingwood.

120 For such a concept of law cf. L. Rosen, Law as Culture (2006) 7, who defines law as a "framework for ordered relationships"; see also K.-H. Ladeur/I. Augsberg, Die Funktion der Menschenwürde im Verfassungsstaat (2008) 23 ("The law as 'boundary,' as prohibition, is not exhausted in laws of right [Rechtsgesetze] in a narrow sense. Paradoxically, it is what first allows acting in society according to rules"). 
Rather than offering a medial history of law, this work is concerned with analyzing the differences that media such as spoken language, writing, printed books, and computer networks have produced and continue to produce within the history and evolution of law and how it is studied. Legal proceedings are impossible without spoken language even today, but spoken language has long since ceased to be the sole medium that defines practical legal culture. If this study makes frequent recourse to historical examples, and particularly to "secondary sources," this is animated by the belief that the relevance of media in the formation of and approach to law at particular historical turning points - such as the inaugural use of writing for legal purposes in Mesopotamia, ancient Israel, Athens or Rome - can thereby be made especially vivid. The choice of historical examples moreover is oriented by the methodological decision to employ such examples only in regard to issues that are still relevant today. Legal Theory and the Media of Law thus promotes enriching legal theory with aspects of media theory in order to provide some orientation for future legal-theoretical research and debate. At the same time, it also attempts to redefine the richness of the European legal tradition and its (ancient) Near Eastern periphery, which today must be understood less as the "heritage of an imperative" and more as the inheritance of a "sheaf of injunctions."121

Specifically, the exposition and explication of our research program may be summarized as follows: Printed books and computer networks will form the subject of parts three and four of Legal Theory and the Media of Law. This first part is primarily concerned with the relationship between "law and language," the second part with the transformation law undergoes when writing comes into play. The latter will demonstrate to what extent the emergence in antiquity both of conditional norms and codes and of all manner of legal expertise is linked to writing as an "arrangement favorable to complexity" in the sense of Luhmann's theory of pre-adaptive advances. ${ }^{122}$ Indeed, if one does not from the outset restrict the concept of law to the idea of "autonomous" law that is professionally written down, but rather turns one's attention to the rules and ordering patterns of a practical culture, then one will be able to discover law in even the earliest oral cultures in the form of pithy, easily memorizable maxims and prohibitions as well as in recurring modes of conduct, such as the resolution of legal conflicts. In oral cultures, however, law is inextricably interwoven with other forms of practical (implicit) knowledge. It is only when writing comes into use and a level of observation distinct from oral legal practice is consolidated that a level of law's self-description through the lens of various forms of professional expertise (as wisdom literature, as a doctrine of divination, as theology, as philosophical and rhetorical legal expertise, as iuris prudentia, etc.) can be separated from the concrete carrying out of a legal (non-arbitrary, non-spontaneous, non-unique) act. Conversely, law itself can only begin to develop more complex forms such as legal propositions when it is written in signs on lasting material (text) and therefore written for the purpose of repeated use (texture), as

121 Referring to Derrida (fn. 100) 955. In particular, the one-sidedness of tracing law back to Rome as its sole reference point must be avoided.

122 Luhmann (fn. 6) $309 \mathrm{f}$. 
a text in the past tense. ${ }^{123}$ It is only with graffiti and writing that the safeguarding, framing, and maintenance of the law begins, tasks that in oral legal proceedings must always be accomplished situationally and locally, within personal relationship and communication networks.

123 Cf. Stetter (fn. 2) 294 (on the distinction between text and texture); see also Faur (fn. 45) 1 ff., who following Émile Benveniste (1902-76) distinguishes between "writing/semantics" and "graffiti/semiotics." 